\title{
Osteopatia na atenção primária à saúde: resultados parciais de uma experiência de educação permanente e alguns efeitos iniciais
}

\author{
Osteopathy in primary health care: partial results of continuing \\ education experience and some initial outcomes
}

Leonardo Mozzaquatro Schneider (https://orcid.org/0000-0003-3743-0365) ${ }^{1}$

Charles Dalcanalle Tesser (http://orcid.org/0000-0003-0650-8289) ${ }^{1}$

${ }^{1}$ Programa de PósGraduação em Saúde Coletiva, Universidade Federal de Santa Catarina. R. Eng. Agronômico Andrei Cristian Ferreira s/n, Trindade. 88040-900 Florianópolis SC Brasil. leonardomozza@gmail.com

\begin{abstract}
This paper presents partial results of a research-intervention, through training of $\mathrm{PHC}$ work teams. Initial consultation was made in a group by HC professionals, and the osteopath then performed the consultation. The socialization and training of practical knowledge and techniques of the osteopathic approach was done between consultations. Multiprofessional teams from three health centers from Florianópolis, southern Brazil, participated in the training, and the process was audio and videorecorded, along with a final interview. Data was analyzed using the Grounded Theory. Apprehending the osteopathic knowledge was a triggering tool for reflective processes about care. Faced with the efficiency and resolution of this approach in practice, participants showed a willingness to transform their acts of care of patients and also their self-care. The professionals argue that the common understanding about self-regulating mechanisms and the inclusion of the tissue mobility in their anamnesis, including the stimulation of endogenous mechanisms, contributed to less protocol-based care, more appropriate care for each case, better multidisciplinary team work, the rational use of additional tests, medication, and surgical procedures.

Key words Osteopathic medicine, Medicalization, Primary Health Care, Physical therapy
\end{abstract}

Resumo Este artigo apresenta resultados parciais de uma pesquisa-intervenção, por meio de capacitação, relativas à socialização de saberes/técnicas da abordagem osteopática para profissionais da Atenção Primária à Saúde (APS), na sua confrontação com os processos de trabalho e cuidado na APS, conforme a lógica da educação permanente em saúde. Participaram das capacitações, equipes multiprofissionais de três centros de saúde de Florianópolis, região sul do Brasil, sendo o processo registrado em áudio e vídeo e acrescido de uma entrevista final. A análise dos dados foi feita por meio da Grounded Theory. A aprendizagem de saberes osteopáticos mostrou-se como instrumento disparador de processos reflexivos acerca do cuidado. Confrontados com a eficácia e resolubilidade percebidas desta abordagem na prática, os participantes demonstraram disposição para transformar seus atos de cuidado consigo mesmo e dentro do seu processo de trabalho. Segundo os profissionais, o entendimento comum sobre os mecanismos de autorregulação e a inclusão do estudo da mobilidade tecidual em sua anamnese contribuíram para o trabalho em equipe envolvendo um cuidado menos protocolar, mais adequado à cada caso, que inclui o estímulo de mecanismos endógenos, o uso racional de exames complementares, medicação e procedimentos cirúrgicos.

Palavras chave Osteopatia, Medicalização, Atenção Primária à Saúde, Fisioterapia 


\section{Introdução}

A osteopatia/medicina osteopática é um estilo clínico peculiar que pode ser definido como um sistema de cuidados à saúde centrado na pessoa, que inclui um senso altamente desenvolvido do toque como um componente significativo para estabelecimento de diagnóstico e conduta terapêutica. Nela, se considera necessário um entendimento avançado da relação entre estrutura e função corporal e é aplicada para otimizar as capacidades de autorregulação, visando a homeostase dos indivíduos por meio de mecanismos endógenos ${ }^{1}$.

No Brasil, a osteopatia foi reconhecida como ocupação pelo Ministério do Trabalho em 2013, em 2011 tornou-se especialidade da fisioterapia ${ }^{2} \mathrm{e}$ no ano de 2015 iniciou-se a tramitação do projeto de Lei PL2778/2015 na câmara dos deputados, que reconhece a osteopatia como ramo específico da saúde e regulamenta a profissão de osteopata. No Sistema Único de Saúde (SUS), foi incluída como Prática Integrativa e Complementar (PIC) em 2017, havendo um incentivo para sua inserção na atenção primária à saúde (APS) ${ }^{3}$. A Política Nacional de Práticas Integrativas e Complementares (PNPIC) $)^{4}$ enfatiza a necessidade de se transformar o modelo de cuidado no sentido da integralidade e humanização do cuidado, em caráter multiprofissional e em conformidade com os princípios e diretrizes estabelecidos para Educação Permanente em Saúde (EPS) ${ }^{5}$, que direciona esforços de aprendizagem para dentro do processo de trabalho.

A adequação da osteopatia à Atenção Primária à Saúde (APS) não é nova e está amplamente fundamentada na sua história fora do Brasil ${ }^{6}$, porém, é ainda pouco explorada neste nível de atenção no Brasil. Este artigo deriva da pesquisa de doutorado em saúde coletiva que envolveu a construção participativa de uma experiência de capacitação na lógica da educação permanente em osteopatia para/com profissionais da APS do município de Florianópolis? ${ }^{7}$ O objetivo deste artigo é apresentar e discutir resultados do processo de pesquisa-intervenção, por meio de capacitação, relativas à socialização/ensino de aspectos dos saberes/técnicas/abordagens osteopáticas para/com profissionais da saúde da família, na sua confrontação com os processos de trabalho e cuidado na APS, conforme a lógica da EPS, na perspectiva dos profissionais envolvidos.

\section{Percurso metodológico}

A pesquisa-intervenção foi pactuada com a Secretaria Municipal de Saúde (SMS) de Florianópolis, incluindo sua Comissão de Práticas Integrativas e Complementares (CPIC), a gestão de atenção básica municipal e os coordenadores e equipes de três de seus Centros de Saúde (CS). Ela foi precedida por 4 meses de exploração do campo do cuidado clínico na APS, em que um pesquisador acompanhou e realizou atendimentos compartilhados com uma equipe de saúde da família uma manhã por semana, objetivando conhecer as principais demandas, tipos de problemas e respectivas abordagens ali utilizadas. Esta foi a base para a proposição e negociação multilateral de capacitações em osteopatia voltadas aos profissionais da Saúde da Família.

As capacitações se organizaram segundo preceitos da EPS, principalmente no que concerne a: lidar com a imprevisibilidade do campo; considerar os interesses e desejos dos participantes; procurar a inserção na realidade cotidiana e profissional dos mesmos; aproximar a aprendizagem da transformação participativa dos contextos estudados e lidar com a resolução de problemas práticos $^{4}$.

Foram realizadas duas ondas de capacitação com carga horária de 32h, divididas em 8 encontros semanais cada uma. Participaram delas 35 profissionais de equipes de saúde da família e núcleos de apoio a saúde da família (NASF), incluindo 3 médicos, 7 enfermeiros, 5 fisioterapeutas, 1 psicólogo, 1 técnico de enfermagem, 10 agentes comunitários, 3 educadores físicos e alguns residentes e acadêmicos de medicina. Participaram também 21 usuários dos CS, que foram atendidos ao longo do processo. A pesquisa foi aprovada pelo comitê de ética em pesquisa com seres humanos e ocorreu dentro do horário de trabalho dos profissionais. Foram utilizados pseudônimos para manter a identidade em sigilo.

As capacitações procuraram ao máximo aproximar a teoria da prática, através de ciclos de ação-reflexão-ação inseridos no processo de trabalho. Cada turno de capacitação (4h) teve sua dinâmica organizada em vivências da seguinte maneira: o grupo elencava casos clínicos (entre seus membros ou de usuários dos CS), havia uma consulta inicial realizada em grupo pelos profissionais do CS e em seguida a consulta era realizada pelo osteopata.

Ao longo dos atendimentos, os profissionais tinham liberdade e estímulo para realizarem questionamentos segundo suas necessidades e 
dúvidas. O osteopata/pesquisador, ao longo dos atendimentos, mantinha sua atenção no paciente e na possibilidade de socializar conhecimentos, reservando um segundo momento para possibilitar aos profissionais que vivenciassem em si, as técnicas utilizadas no caso atendido. A partir disto, surgiam espontaneamente assuntos e diálogos entre os participantes. Estes, foram organizados por meio de dinâmicas reflexivas e posteriormente sintetizados em mapas mentais (organizando graficamente um conjunto de palavras-chave) ${ }^{8}$ e as conversas foram registradas em materiais audiovisuais.

As dinâmicas reflexivas envolviam a construção de perguntas disparadoras conduzidas pelo pesquisador. Para a construção das perguntas disparadoras o pesquisador revisitou sistematicamente as anotações e gravações do encontro anterior, atento as narrativas que indicassem estranhamentos, lacunas ou tensionamentos do grupo frente aquilo que estava sendo vivenciado. As perguntas procuravam iluminar as situações ainda não compreendidas pelos mesmos, permitindo que o grupo se expressasse em relação àquilo que ainda não parecia muito bem estabelecido, organizado ou até aceitável do seu ponto de vista. Houve um esforço consciente por parte do pesquisador em aproximar a intervenção ao dia a dia, seja por meio da experiência do próprio corpo dos participantes, suas queixas e seu uso diário ou aproximando-se das situações reais nas consultas compartilhadas dentro do serviço. $\mathrm{Ou}$ tro esforço metodológico foi deixar ao máximo a teorização a cargo dos participantes e suas interpretações de tal forma que criassem vocabulários próprios acerca das técnicas e daquilo que fora vivenciado.

Encerrados os encontros de capacitação, todos os materiais produzidos foram revisitados seguindo a ordem cronológica em que foram feitos. Depois foi realizada uma rodada de entrevistas visando captar os significados e sentidos atribuídos pelos participantes a sua experiência na capacitação e em sua prática diária. $\mathrm{O}$ roteiro da entrevista continha perguntas de caráter amplo e aberto no intuito de não influir nas respostas mas sim de situar os profissionais frente à capacitação (no passado: o que foi a capacitação para você?; presente: você percebe alguma mudança na sua relação com a saúde?; e futuro: qual o impacto da capacitação para o serviço se prosseguirmos com ela?). As entrevistas ocorreram em sequência por conveniência (facilidade de encontro, agendamento e realização) até ser percebida a saturação dos dados, sendo 20 os entrevistados. A análise do material foi orientada pela Grounded Theor ${ }^{9}$, por permitir explorar a diversidade dos dados de forma criativa, abrangente e interativa. Esta metodologia nos instrumentalizou a partir dos achados empíricos para buscar conceitos e referências teóricas e não o contrário. Os dados foram transcritos, agrupados, categorizados, comparados entre si, interpretados e discutidos com autores capazes de aprofundar e fortalecer as relações entre as categorias temáticas ${ }^{9}$.

\section{Resultados e discussão}

As categorias iniciais emergentes do processo de nossa pesquisa/intervenção remetem aos seguintes contextos: processo de trabalho; relações de cuidado consigo e com o outro; crenças e pressupostos dos participantes sobre saúde; aprendizagem em saúde; e modelo de atenção compartilhado pelos profissionais do serviço. Ao analisarmos e trabalharmos estas categorias iniciais, por meio das dinâmicas reflexivas nas capacitações, foram produzidos mais materiais que em análise final geraram os tópicos que fazem parte de nossos resultados.

\section{Daquilo que se mostrou socializável da osteopatia para profissionais da APS}

Os conteúdos que foram socializados são apresentados como parte de nossos resultados e não como parte do método, pois, a triagem das abordagens passiveis de socialização se deu no calor das intervenções. Tornou-se mais importante instrumentalizar uma atitude investigativa acerca do movimento e das capacidades de auto-regulação (aspectos subdesenvolvidos no saber biomédico), estabelecendo critérios simplificados para sua eleição (abaixo sintetizados), do que nomear uma série de técnicas específicas para cada segmento corporal. Esta atitude incluiu alguns critérios presentes na racionalidade osteopática e que pareceram não estar presentes no estilo clínico utilizado pelos profissionais dos serviços.

Três principais critérios se mostraram relevantes de serem socializados: 1) avaliação da mobilidade dos tecidos, explorando palpatoriamente os tecidos mais tensos e os principais eixos de movimento partindo da flexão e extensão das articulações; 2) observação e avaliação da relação do organismo como um todo e com suas partes, percebendo possíveis relações anatômicas, principalmente no que se refere a vascularização e inervação, partindo da coluna vertebral para os 
membros, bem como considerando como os aspectos emocionais e sociais podem ter relação com as tensões encontradas; 3 ) observação da relação entre a função (incluindo o movimento realizado nas atividades laborais, de lazer e convívio) e os sinais e sintomas, questionando sobre onde (contexto) e quando(tempo) o problema se manifesta, quais os movimentos que agravam e quais trazem conforto ${ }^{7}$.

\section{Para além do prognóstico biomédico: o resgate da curiosidade clínica e a surpresa da eficácia dos mecanismos de autorregulação}

A questão da avaliação clínica para além do modelo biomédico foi levantada por boa parte dos profissionais após a capacitação:

Eu pude aprofundar essa parte investigativa... do porque, dessa linha histórica, de tentar entender quando ela surgiu e como. Não só do ponto de vista mecanicista, biomecânico, mas considerar todo o contexto social de vida do paciente... (Caio, educador físico).

A aprendizagem da osteopatia se mostrou um dispositivo capaz de gerar processos reflexivos acerca da clínica, da importância de se testar as hipóteses diagnósticas e de verificar se a visão de futuro construída para cada caso (prognóstico) converge ou diverge de sua evolução. Isto pois, no momento em que os profissionais reavaliaram os prognósticos por eles esperados na primeira consulta e confrontaram com a evolução após a abordagem osteopática, observaram a eficácia ou ineficácia do modelo clínico que utilizam diariamente no seu processo de trabalho.

A osteopatia apresenta evidências de sua eficácia em diversas patologias (lombalgias, cefaleias, refluxo em bebês, por exemplo), todavia boa parte dos estudos carecem de ainda de padrão de qualidade metodológica ${ }^{7,10}$. As manipulações têm o objetivo de restabelecer a mobilidade dos tecidos corporais. Seus mecanismos são complexos e, por isso, coexistem modelos explicativos (biomecânico, vascular, neurológico, biopsicossocial e bionergético) $)^{1,7}$.

Em nosso estudo os relatos de melhora e eficácia durante a capacitação foram fortalecedores da confiança do grupo na aprendizagem e na capacidade inerente de autocura do corpo. Para a educação permanente, a transformação não envolve apenas a pedagogia e os processos de ensino e aprendizagem, mas também uma incorporação crítica de saberes/técnicas, padrões de escuta, relações estabelecidas com os usuários e entre os profissionais, a partir da eficácia da clínica produzida ${ }^{10,11}$ :

O que eu pude observar foi uma resolução muito grande nos casos de dores crônicas e não crônicas que a gente atendeu, com uma melhora bem significativa... isso foi o que me marcou bastante no curso. (Pedro, enfermeiro).

$\mathrm{Na}$ tipologia desenvolvida por Merhy ${ }^{12}$, que compreende as densidades tecnológicas no campo da saúde, a osteopatia parece se enquadrar em um espaço até então pouco habitado ou reconhecido, uma espécie de lacuna entre as tecnologias ditas leves-duras, (que incluem os saberes clínicos estruturados, envolvendo a eficácia clínica, a semiologia, a fisiologia e a anatomia, aplicados no cuidado) e as tecnologias leves (questões relacionais, como o acolhimento e o estabelecimento de vínculos e parcerias entre profissionais e destes com usuários). Isso porque, embora a osteopatia se apresente com uma boa quantidade de saberes relacionados à clínica dita "dura", incluindo saberes fisiológicos e epidemiológicos comuns à biomedicina, por outro lado possui todo um grande componente de trabalho vivo em ato que busca criar relações que integrem as informações duras e leves-duras com as sensações e referenciais do próprio indivíduo, aproximandose de sua singularidade e facilitando o resgate de uma maior autonomia frente à seu corpo e suas questões de saúde.

\section{Da ampliação do olhar clínico ao trabalho em equipe}

Para os profissionais, a socialização do saber osteopático em um contexto multiprofissional incluiu a valorização de diferentes olhares, a ampliação da clínica na prática e o fortalecimento do trabalho em equipe. Ao atuarmos, via educação permanente, na aprendizagem de diferentes profissionais, fortalecemos as possibilidades da transformação do processo de trabalho a partir do consenso sobre a inclusão de novas estratégias de cuidado:

Não foi como um livro que tu pega uma linha e vai lendo, mais de uma forma que todo mundo consegue entender e trabalhar junto (Fabiane, ACS).

A transformação necessária dos serviços de saúde, no sentido do fortalecimento do trabalho em equipe centrado na pessoa, por meio de formação interdisciplinar, é bastante reconhecida ${ }^{13}$. Para Merhy et al. ${ }^{14}$, o acompanhamento e discussão coletiva de casos clínicos é um dispositivo potente para identificar a complexidade dos pro- 


\section{Abrindo os olhos para o fenômeno da catastrofização}

Os profissionais perceberam ao longo do processo, o quanto o exercício da abordagem biomédica pode gerar interpretações equivocadas, associadas a narrativas sobre prognóstico catastrófico e tendo como consequência a diminuição das atividades do paciente, medo do movimento e consequente piora no quadro como um todo:

A gente percebeu a importância de observar como a gente fala... porque se a gente não explica ele vai passar a vida toda sem fazer mais nada (Fernanda, fisioterapeuta).

A capacitação em muitos momentos confrontou os participantes com os fenômenos associados da cinesiofobia e catastrofização. Estes são conceitos comuns na osteopatia mas pouco discutidos na saúde coletiva, na biomedicina e na APS, e podem ser observados como uma faceta da biomedicalização da vida ${ }^{15}$. O fenômeno da catastrofização pode ser caracterizada por geração ou reforço de antecipação ou expectativa de desfechos negativos por parte dos pacientes. Já a cinesiofobia é definida como medo de movimentar-se. Eles têm relação coma qualidade da interação profissional-usuário e são relativos às expectativas de melhora ou piora do quadro do paciente. A conduta clínica e a qualidade da relação profissional/usuário, incluindo a comunicação verbal e não verbal, podem reforçar crenças limitantes, aumentar a dor, gerar ansiedade e estresse $\mathrm{e}^{16,17}$ :

Para nós foi uma surpresa... o médico falou para ela que ela ia piorar com o tempo, que ela não ia mais engolir... Aí a depressão veio a aflorar muito. O que marcou para mim, foi que uma coisa que ela gostava muito de fazer era caminhar na praia e o médico falou para ela "não, tu não pode caminhar na praia”... Ela era muito ativa e a partir daquele acidente ela passou a viver aquilo que o médico falava para ela viver... (Clara, técnica de enfermagem).

Em muitas situações, o processo de catastrofização desestimula o paciente a seguir com sua vida livre de crenças de incapacidade. Tais crenças geralmente ganham força na relação clínica por meio de recomendações de repouso prolongado e retirada irracional de atividades físicas, sendo respaldadas em diagnósticos de patologias, legitimados ou não por exames complementares e indicações de estratégias terapêuticas vitalícias ${ }^{17,18}$. Este processo gera atrasos ou impede a recuperação, além de gerar aumento pela procura dos serviços de saúde convencionais e não convencionais, maior consumo de medicamentos e maior realização de cirurgias desnecessárias $^{18}$. Isso por vezes é induzido por saberes biomédicos estabelecidos, relativos à cronificação de doenças ou situações para as quais não se tem cura (segundo o modelo dominante) e subliminarmente há um implícito (inscrito no saber e na cultura profissional) de evolução para pior, sobretudo quando há diagnósticos de lesões ou doenças crônicas tecnicamente confirmados por exames complementares.

\section{Quantidade X qualidade dentro do serviço}

Um importante obstáculo à mudança das práticas de cuidado foi a rígida organização do processo do trabalho em relação ao tempo e a demanda. Esse fato, por um lado, aponta para um achado recorrente na literatura relativo ao subdimensionamento da APS e a sobrecarga da demanda ${ }^{19}$. Por outro lado, indica que modelos de aprendizagem permanente devem ter continuidade por se tratar de espaços de encontro acerca de temas que não se encerram, por serem inerentes ao trabalho e necessitarem ciclos de experimentação/reflexão/ação para alcançarem as devidas negociações nas agendas visando as mudanças necessárias:

[...] aqui no Centro de Saúde, para a gente fazer o que aprendeu no curso, eu precisaria de mais de 10 min de consulta. Pensando que a minha agenda é de 10 a 15 min e que é alta a demanda... pra gente é muito mais fácil dar a receita com os medicamentos do que a gente posicionar, avaliar, conversar e testar. Ao mesmo tempo que eu estou com a paciente, estou pensando no meu atraso e nas pessoas que estão lá fora esperando... que eu preciso atender bem rápido. (Roberta, enfermeira).

O cuidado em saúde é um ato singular, sendo imprescindível que o ser cuidado e o ser cuidador se encontrem em interação qualitativamente produtiva ${ }^{20,21}$. Esta interação envolve ações, atitudes e comportamentos guiados por fundamentação científica, experiência, intuição e pensamento crítico. Este processo necessita que a atenção 
do profissional esteja na relação com o outro, visando promover, manter e/ou recuperar não apenas sua integridade física, mas sobretudo sua dignidade e totalidade humanas ${ }^{21,22}$. Do contrário, deixados às normas e ao automático, sabe-se que os trabalhadores tendem a reproduzir o hegemônico, tendem a produzir descuidado ${ }^{12,23}$.

Neste contexto o profissional vê a sua atenção dividida entre metas externas e o exercício de se colocar disponível a perceber o outro, colocando-se no lugar deste para estabelecer relações empáticas e que transmitam algo a mais do que informações técnicas protocolares.

Por conta da demanda, a gente às vezes atropela o processo terapêutico, quer fazer tudo muito rápido.... e a capacitação traz de volta a questão do toque e a importância de acolher aquela pessoa, não apenas a dor da pessoa mas o que ela está trazendo com um olhar mais sensivel, mais integrativo... (Joana, fisioterapeuta).

A habilidade relacional de construção de vínculo pode determinar a escolha deste ou daquele profissional como centro do cuidado no acompanhamento longitudinal, todavia isto pareceu não estar sendo computado nos indicadores de produtividade do serviço. Em nosso estudo o trabalho em saúde, repleto de significados, vínculo e pactuações, como se preconiza para uma maior eficácia da APS, se mostrou desvalorizado. Isto dificulta a transformação do modelo de atenção no que compete a introduzir olhares singulares e não protocolares, como propõe o estilo clínico osteopático. Nas palavras da técnica de enfermagem, Clara:

[...] parto muito de olhar, [...] da pessoa em si, não só da doença [...], do indivíduo como um todo.... a equipe me pergunta, "porque os pacientes só querem vir quando você está?" Eu sou muito cobrada por essa atitude [...] porque tem aquela coisa... "vamos, vamos, não dá tempo, tem uma lista enorme te esperando... não é aqui que você tem que fazer isso"... o paciente chegou com uma receita, você confere, administrou, "pá, pum" e manda embora. [...] essa coisa de números, números e números! Isso me deixa angustiada como profissional. (Clara, técnica de enfermagem).

Segundo Scherer et al..$^{24}$ para a superação do modelo de cuidado biomédico são necessárias ferramentas cognitivas afiadas para desempenhar todas as funções demandadas em seu dia a dia com qualidade e sensibilidade, o que determina um maior 'uso de si'. Em nosso percurso, observamos que os trabalhadores mais atentos às singularidades acabavam sendo sobrecarregados e cobrados a aderir a uma contraditória produ- ção em série de procedimentos. Contatore et al. ${ }^{25}$ afirma que existe um obstáculo para a efetivação das PIC, pois os serviços estão vinculados a uma política que privilegia evidências quantitativas em detrimento das qualitativas.

\section{Refletindo sobre as condutas clínicas e a conquista de maior autonomia com compartilhamento de responsabilidades}

Quando em contato com os recursos terapêuticos apresentados na capacitação, os profissionais pareceram motivados a participar mais do próprio serviço, no sentido de buscar e testar novas possibilidades terapêuticas ao invés de simplesmente aderir a condutas que em sua experiência prévia não se mostraram satisfatórias:

A capacitação foi uma maneira de ajudar o próximo de ter uma visão... como aconteceu com a minha amiga, ela chegou falando: eu vou fazer uma tomografia e uma ressonância; e eu falei: espera, calma aí, vamos ver se tem alguma alternativa... foi uma forma de eu ter essa autonomia de falar isso. (Fabiane, ACS).

A autonomia em recomendar ou questionar determinada estratégia de cuidado, seja para si ou para o próximo, pode gerar uma desconfiança quanto a segurança envolvida nesse processo. Será que todos os profissionais têm condição de realizar determinados questionamentos? Quem tem o poder sobre essas decisões? Em nosso ver, a experiência dos profissionais em acompanharem diferentes casos ao longo do tempo, traz um valioso arcabouço de vivências capazes de contribuir para uma tomada de decisão segura e mais assertiva acerca da escolha de tratamento. Por outro lado, é previsível e inevitável que os profissionais tragam suas experiências prévias, tanto vivenciadas em si quanto testemunhadas no acompanhamento de outros casos, como elementos norteadores das recomendações em seu ato de cuidado com os usuários.

Tratando da construção de uma relação de cuidado que envolva autonomia e compartilhamento da tomada de decisão, Menéndez ${ }^{26}$ recupera um tipo de comportamento caracterizado pelo não cumprimento da prescrição, que se conhece como o caso do indivíduo "bem informado". Um descumprimento não por ignorância das suas consequências ou por não entender a prescrição, senão devido, por um lado, à quantidade de informação técnica que possui este tipo de paciente, e por outro, que sua modificação do tratamento obedece a sua própria experiência. $\mathrm{O}$ indivíduo decide aumentar, reduzir a dose ou 
espaçá-la segundo seu conhecimento e sua experiência, o que não oculta e sim discute com a equipe. Fazendo isto, este usuário ou profissional não questiona o "poder médico" nem a eficácia da biomedicina, é um partidário da mesma, não lhe interessa discutir o poder na relação médico/ paciente, e sim melhorar a saúde, controlando o melhor possível o padecimento crônico. Este tipo de usuário ou profissional se caracteriza por seu saber e também pelo aprendizado com sua própria experiência de enfermidade e atenção ${ }^{26}$.

Essa postura relacional estimulada na capacitação envolve uma atitude questionadora e dialógica que busca fundir as informações técnicas e experiências próprias para uma decisão compartilhada e responsável, e revela uma prática entre profissionais e usuários que é sistematicamente velada e por isso não notificada nem tampouco tecnicamente desenvolvida. Essa prática tem relação com a utilização de medicamentos já pertencentes ao arcabouço de autoatenção dos usuários, utilizados na prática diária para sintomas recorrentes como dores músculo-esqueléticas, cefaleias, problemas gastro-intestinais comuns como azia, refluxo, má digestão, gases, prisão de ventre, etc. Na capacitação, houve casos em que a avaliação osteopática foi utilizada para o reconhecimento de diagnósticos diferenciais (reformulando hipóteses diagnósticas) e estratégias terapêuticas, o que possibilitou um redirecionamento de certas estratégias de autoatenção. Nas palavras de Cilene:

[...] eu estava com uma dor abdominal, o médico tinha pedido os exames de sangue e dado antibiótico (sem qualquer melhora). Achávamos que era cistite, mas depois (após a avaliação palpatória) a gente veio a descobrir que eram gases e melhorou. (Cilene, ACS).

Nesse caso, a avaliação osteopática apontou para um tensionamento e perda de mobilidade dos tecidos na região do intestino grosso e aumento de gases. A ACS por conta própria, escolheu uma medicação que já havia utilizado para gases e em dois dias estava sem os sintomas que já perduravam por duas semanas, mesmo já tendo realizado o uso de antibiótico sem nenhum efeito.

Esta capacidade de estabelecer hipóteses diagnósticas baseadas no estudo de sinais fisiológicos caracteriza a osteopatia desde seu nascimento, no século XIX. Flexner ${ }^{27}$, mesmo sendo abertamente avesso à esta abordagem, manteve a osteopatia como escola médica em seu histórico relatório em 1910, pois, observou que, "na seita, os osteopatas eram treinados a reconhecer uma enfermidade e a diferenciar uma patologia da outra tão cuidadosamente quanto qualquer outro médico" ${ }^{27}$ (p.125).

Este assunto toca uma importante barreira referente a autonomia sobre a tomada de decisão sobre utilização de estratégias terapêuticas medicamentosas e outras que tencionam os territórios circunscritos pela atuação exclusiva de profissionais/especialistas ou a gradual dissolução de saberes em campos de atuação conjunta, dialogada e multiprofissional. A simples negação desse fenômeno parece apenas distanciar o conhecimento empírico do saber técnico, o que torna o cuidado mais ineficaz e diminui o diálogo e o vínculo entre as partes envolvidas.

Tesser $^{28}$ destaca quatro eixos onde as PIC potencialmente podem contribuir para a promoção de saúde. Pudemos observar três destes eixos em nossa intervenção. $\mathrm{O}$ primeiro envolve um certo “empoderamento do coletivo" para que indivíduos e coletividades possam participar ativamente na construção de uma vida e uma sociedade mais saudável. Este eixo pode ser observado tanto no fortalecimento do trabalho em equipe e na sensação de autonomia em procurar alternativas e estratégias menos invasivas como forma de terapêutica. O segundo eixo compreende concepção de saúde positiva e ampliada, o que pode ser observado em diversos relatos onde os participantes trouxeram a importância de compreender o contexto incluindo as histórias de vida de cada pessoa, bem como quando se depararam com a eficácia produzida ao promover mecanismos de autocura por meio da flexibilização dos tecidos (técnicas manuais osteopáticas). E o terceiro eixo refere-se à transformação das práticas pedagógicas em algo mais dialógico e menos diretivo ${ }^{28}$.

\section{A reestruturação do saber a partir da vivência da abordagem osteopática em si e no outro}

Os profissionais reconheceram o fomento de uma postura "humana" durante a capacitação. Esta característica é esperada de todo profissional exercite no cuidado clínico aos usuários, ou seja, um interesse genuíno, solidário e empático pelo outro, nas palavras de Fabiane "acima de tudo, foi muito humano” e segundo Fernanda:

acho que você foi muito verdadeiro com a gente e com os pacientes. Tu não veio aqui só para mostrar o trabalho, aplicar o teu trabalho, tu se importou mesmo com os pacientes.

A vivência da abordagem osteopática pareceu acessar parte da subjetividade e dos afetos envol- 
vidos no ato de cuidado, como trabalhadores da saúde e como pacientes. Para Bessa et al. ${ }^{29}$, afetos envolvidos no processo de trabalho em saúde são sentimentos que se fazem com base na história pessoal de cada um e na imagem produzida pelo serviço ou pelo profissional. Esses afetos podem contribuir ou não para a eficácia da conduta terapêutica e para a manutenção da vida em cada pessoa afetada, o trabalhador ou o usuário. É imprescindível considerar os afetos na aprendizagem em saúde, sobretudo no estabelecimento das interações intersubjetivas dos cuidados e de sua aprendizagem.

Para Ceccin e Feuerwerker ${ }^{30}$, das atividades de educação permanente, das problematizações do pensar-agir-perceber e de sua interpretação, emerge como aprendizagem significativa, a invenção de si. Nesse processo há a dissolução de identidades, de formas de agir, dentro e também fora do trabalho, o que reconfigura novas subjetividades acerca dos assuntos vivenciados. Estas novas metodologias produzem uma ruptura, pois põem as pessoas frente a si mesmas, substituem um processo educativo heterônomo por um processo mais autônomo. Em nosso processo, a aprendizagem da osteopatia, por meio da vivência desta abordagem em si e no outro, mostrou-se um disparador de processos reflexivos indutores de transformar em alguma medida o cuidado e a si próprio. Nas palavras da enfermeira Roberta: "Aqui eu tenho uma reflexão sobre mim mesma", e para João, médico de Família, a capacitação conseguiu impactar na qualidade de sua identidade profissional: "Depois desses dois meses de capacitação, eu me sinto um profissional melhor".

\section{Sinais de superação do modelo biomédico}

Ao longo da capacitação, os profissionais puderam visualizar possibilidades de superação do modelo biomédico vigente e alguns de seus problemas mais evidentes para além da teoria. A formação de enfermagem, por exemplo, tem sua formação mais recente inclinada a competências e conceitos característicos de APS, porém, parece haver ainda obstáculos integração entre teoria e prática destes conceitos dentro da formação ${ }^{31}$. Em nosso estudo os profissionais trouxeram exemplos de aplicação da abordagem na rotina de trabalho, que incluíam assuntos relativos à diferenciação diagnóstica, testagem de hipóteses, superação de conduta puramente protocolar, uso racional de fármacos e exames complementares, e consequente resolubilidade. Os participantes foram praticamente unânimes sobre uma mudança de olhar na prática do cuidado. Segundo as enfermeiras Isabel: "Uma nova forma de ver o cuidado, uma outra vertente do cuidado", para Diana: “a gente vê que não é algo teórico...”, e para Roberta: "Na capacitação a gente já muda o olhar, a gente testa... dá um olhar diferenciado, não só aquela questão engessada".

Por fim, quando questionados sobre qual seria o impacto desta estratégia de educação permanente a longo prazo, os profissionais apresentaram elementos que apontam no sentido da mudança da cultura envolvida no ato de cuidado, tanto por parte dos profissionais quanto da população. As falas vieram acompanhadas de um repertório relacionado ao que atualmente se defende como "boas práticas":

Vai diminuir a demanda por exemplo de remédio para a dor, pra ansiedade... É um curso que ensina a perceber a pessoa como um ser humano total. (Isabel, enfermeira).

\section{Considerações finais}

O objetivo de nossa pesquisa/intervenção foi procurar transformar o processo de trabalho, no sentido de fomentar ações terapêuticas mais resolutivas, por meio de capacitações sobre a abordagem osteopática para equipes de APS e NASF. O pesquisador teve o comprometimento metodológico em manter-se inserido na prática, no corpo e no dia a dia do trabalhador. Para tal, não foram utilizados muitos momentos teóricos, nem tampouco a separação dos grupos de aprendizagem em diferentes profissões, como é comum. A estratégia pareceu facilitar a instrumentalização da avaliação e do agir profissional focado na totalidade de cada ser humano, recolocando a técnica em um "segundo plano", no sentido de ficar em uma posição adequada, a serviço dos sujeitos, que a praticam ou acessam (ou não), com maior ou menor expertise. Também permitiu a socialização da osteopatia como uma abordagem e não apenas como um conjunto de técnicas isoladas. $\mathrm{O}$ processo aqui sintetizado e analisado parece ter conseguido motivar os profissionais a transformarem em algum grau seu agir profissional, $\mathrm{o}$ que pode vir a ter algum impacto em indicadores do serviço. $\mathrm{O}$ acompanhamento de indicadores de impacto não foi um objeto avaliado neste estudo, assim se sugere para estudos futuros que sejam acompanhados indicadores simples como taxas de dispensação de medicação, utilização de exames complementares, satisfação dos usuários, 
etc. Nosso estudo indica que pelo menos parte do conjunto dos saberes e técnicas da osteopatia podem ser socializados, aprendidos e praticados de forma segura pelas equipes de APS, e que isto potencialmente amplia sua compreensão clínica, o centramento na pessoa, favorece o trabalho em equipe e aumenta resolubilidade do serviço.

\section{Colaboradores}

\section{Referências}

Ambos os autores participaram de todas as etapas da construção do manuscrito. Desde sua concepção, passando pela estruturação, revisão de literatura, construção do método, pactuação com os parceiros e participantes, capacitação, coleta, entrevistas, análise de dados, escrita, conclusões e revisões.

1. World Health Organization (WHO). Benchmarks for training in traditional /complementary and alternative medicine: benchmarks for training in osteopathy. Geneva: WHO library; 2010.

2. Conselho Federal de Fisioterapia e Terapia Ocupacional (COFFITO). Resolução no 398, de 03 de agosto de 2011. Disciplina a especialidade profissional osteopatia e dá outras providências. Diário Oficial da União 2011; 24 nov.

3. Brasil. Portaria $n^{\circ} 145$, de 11 de janeiro de 2017. Altera procedimentos na Tabela de Procedimentos, Medicamentos, Órteses, Próteses e Materiais Especiais do SUS para atendimento na Atenção Básica. Diário oficial da União; 2017.

4. Brasil. Ministério da Saúde (MS). Secretaria de Atenção à Saúde. Departamento de Atenção Básica. Politica Nacional de Picas Integrativas e Complementares no SUS - PNPIC-SUS. Brasília: MS; 2006.

5. Brasil. Ministério da Saúde (MS). Secretaria de Gestão do Trabalho e da Educação na Saúde. Departamento de Gestão da Educação em Saúde. Política Nacional de Educação Permanente em Saúde. Brasília: MS; 2009.

6. Gevitz N. The transformation of osteopathic medical education. Acad Med 2009; 84(6):701-706.

7. Schneider LM. Osteopatia na Atenção Primária à Saúde no município de Florianópolis: uma experiência de matriciamento e educação permanente [tese]. Florianópolis: Universidade Federal de Santa Catarina; 2018.

8. Buzan T. The mind map book, full colour illustrated edition. Londres: Pearson Education Group; 1993.

9. Strauss A, Corbin J. Basics of qualitative research: grounded theory - procedures and techniques. California: Sage Publication; 1990. 
10. Steel A, Sundberg T, Reid R, Ward L, Bishop F, Leach $\mathrm{M}$, Cramer H, Wardle J, Adams J. Osteopathic manipulative treatment: A systematic review and critical appraisal of comparative effectiveness and health economics research. Musculoskeletal Sci Pract 2017; 27:165-175.

11. Miccas FL, Batista SHSS. Educação permanente em saúde: metassíntese. Rev Saude Publica 2014; 48(1):170-185.

12. Merhy EE. Saúde, a cartografia do trabalho vivo. São Paulo: Hucitec; 2002.

13. Frenk J, Chen L, Bhutta ZA, Cohen J, Crisp N, Evans T, Fineberg H, Garcia P, Ke Y, Kelley P, Kistnasamy B, Meleis A, Naylor D, Pablos-Mendez A, Reddy S, Scrimshaw S, Sepulveda J, Serwadda D, Zurayk H. Health professionals for a new century: transforming education to strengthen health systems in an interdependent world. Lancet 2010; 376(9756):1923-1958.

14. Merhy EE, Feuerwerker LCM, Ceccim RB. Educación permanente en salud: una estrategia para intervenir en la micropolítica del trabajo en salud. Salud Colect 2006; 2(2):147-160.

15. Tesser CD. Medicalização social (I): o excessivo sucesso do epistemicídio moderno na saúde. Interface (Botucatu) 2006; 10(19):61-76.

16. Darlow B, Fullen BM, Dean S, Hurley DA, Baxter GD, Dowell A. The association between health care professional attitudes and beliefs and the attitudes and beliefs, clinical management, and outcomes of patients with low back pain: a systematic review. Eur J Pain 2012; 16:3-17.

17. Benedetti F, Lanotte M, Lopiano L, Colloca L. When words are painful: unraveling the mechanisms of the nocebo effect. Neuroscience 2007; 147(2):260-271.

18. Main CJ, Foster NE, Buchbinder R. How important are back pain beliefs and expectations for satisfactory recovery from back pain? Best Pract Res Clin Rheumatol 2010; 24(2):205-217.

19. Tesser CD, Norman AH, Vidal TB. Acesso ao cuidado na Atenção Primária à Saúde brasileira: situação, problemas e estratégias de superação. Saude Debate 2018; 42(1):361-378.

20. Morais FRC, Silva CMC, Ribeiro MCM, Pinto NRS, Santos I. Resgatando o cuidado de enfermagem como prática de manutenção da vida: concepções de Collière. Rev Enferm 2011; 19(2):305-310.

21. Formozo AG, Oliveira CD, Costa LT, Gomes A. As relações interpessoais no cuidado em saúde: uma aproximação ao problema. Rev Enferm 2012; 20(1)124127.

22. Neves EP. As dimensões do cuidar em enfermagem: concepções teórico-filosóficas. Rev Enferm 2002; 6(1):79-92.

23. Merhy E, Feuerwerker LCM, Cerqueira P. Da repetição à diferença: construindo sentidos com o outro no mundo do cuidado. In: Franco TB, Ramos VC. Afecção e Cuidado em Saúde. São Paulo: Hucitec; 2010. p. 60-75.
24. Scherer MDA, Oliveira NA, Pires DEP, Trindade LL, Gonçalves ASR, Vieira M. Aumento das cargas de trabalho em técnicos de enfermagem na atenção primária à saúde no brasil. Trab Educ Saude 2016; 14(1):89104.

25. Contatore OA, Barros NF, Durval MR, Barrio PCCC, Coutinho BD, Santos JA, Nascimento JL, Oliveira SL, Peres SMP. Uso, cuidado e política das práticas integrativas e complementares na Atenção Primária à Saúde. Cien Saude Colet 2015; 20(10):3263-3273.

26. Menéndez EL. Modelos de atención de los padecimientos: de exclusiones teóricas y articulaciones prácticas. Cien Saude Colet 2003; 8(1):185-207.

27. Flexner A. Medical education in the United States and Canada: a report to the Carnegie Foundation for the advancement of teaching. Nova York: The Carnegie Foundation for the Advancement of Teaching; 1910.

28. Tesser CD. Práticas complementares, racionalidades médicas e promoção da saúde: contribuições poucos exploradas. Cad Saude Publica 2009; 25(8):1732-1742.

29. Bessa JMS, Muniz PD, Dias QPH, Alves PAG, Pereira SFS, Cavalcante CM. Promoção da Saúde Mental - Tecnologias do Cuidado: vínculo, acolhimento, co-responsabilização e autonomia. Cien Saude Colet 2011; 16(7):3051-3060.

30. Ceccim RB, Feuerwerker LCM. O quadrilátero da formação para a área da saúde: ensino, gestão, atenção e controle social. Rev Saude Colet 2004; 14(1):41-65.

31. Magnago C, Pierantoni CR. A formação de enfermeiros e sua aproximação com os pressupostos das Diretrizes Curriculares Nacionais e da Atenção Básica. Cien Saude Colet 2020; 25(1):15-24.

Artigo apresentado em 22/11/2018

Aprovado em 20/04/2020

Versão final apresentada em 22/04/2020

Editores-chefes: Romeu Gomes, Antônio Augusto Moura da Silva 